\title{
MicroRNA-183 and microRNA-141 are potential risk factors for poor prognosis in patients with nasopharyngeal carcinoma
}

\author{
JUNSHENG LIAN, YUJIE LI and MIN YU \\ Department of Otolaryngology Head and Neck Surgery, Zhengzhou Central Hospital \\ Affiliated to Zhengzhou University, Zhengzhou, Henan 450007, P.R. China
}

Received April 16, 2018; Accepted October 22, 2018

DOI: $10.3892 / \mathrm{ol} .2018 .9650$

\begin{abstract}
This study investigated whether microRNA-183 and microRNA-141 in nasopharyngeal carcinoma (NPC) lesions are potential risk factors for poor prognosis. A total of 317 NPC patients admitted to Zhengzhou Central Hospital Affiliated to Zhengzhou University from January 2010 to March 2015 were included. Reverse transcription-quantitative PCR (RT-qPCR) was used to detect the expression of microRNA-183 and microRNA-141 in lesions and adjacent tissues, and the relationship between the microRNA-183 and microRNA-141 expression levels and prognosis was analyzed. The expression levels of microRNA-183 and microRNA-141 in lesions were significantly higher than those in adjacent tissues $(\mathrm{p}<0.05)$. Patients with distant metastasis had significantly higher expression levels of microRNA-183 and microRNA-141 than patients without distant metastasis $(\mathrm{p}<0.01)$. Patients with disease-free survival (DFS) $<3$ years showed significantly higher expression levels of microRNA-183 and microRNA-141 than those with DFS $\geq 3$ years $(\mathrm{p}<0.01)$. NPC patients with high expression levels of microRNA-183 and microRNA-141 showed poor prognosis. MicroRNA-183 and microRNA-141 may play an important role in the distant metastasis of NPC, and have a great impact on prognosis.
\end{abstract}

\section{Introduction}

Incidence of nasopharyngeal carcinoma (NPC) in southern China is high and NPC is a common head and neck malignancy (1). The etiology of the disease varies, and EB virus infection, genetic and environmental factors all contribute to its occurrence (2). Incidence rate of NPC has reached $10 / 300,000$ (3). More than half of the patients are in advanced stages at the time of diagnosis, and $\sim 1 / 3$ of patients have a

Correspondence to: Dr Junsheng Lian, Department of Otolaryngology Head and Neck Surgery, Zhengzhou Central Hospital Affiliated to Zhengzhou University, 195 Tongbai Road, Zhengzhou, Henan 450007, P.R. China

E-mail: jz46q3@163.com

Key words: nasopharyngeal carcinoma, microRNA-183, microRNA-141, prognosis, distant metastasis survival period of $<5$ years (4). NPC has the characteristics of rapid growth, high degree of malignancy, and is prone to early metastasis. Distant metastasis is the main cause of death after radiotherapy, and $\sim 60-70 \%$ of patients are diagnosed with distant metastases (5). Tumor metastasis is the detachment of the tumor cells from their primary site to traffic through blood vessels or lymphatic vessels, reach distant positions and form tumors of the same nature. In this process, low level of E-cadherin reduces intercellular adhesion, induces epithelial-mesenchymal transition, and promotes invasion and metastasis of tumor cells (6).

MicroRNA is a group of short single-stranded RNAs identified in eukaryotic cells with pivotal roles in the regulation of post-transcriptional gene processing (7). Increasing number of studies have shown that microRNA plays an important role in regulating tumor invasion and metastasis (8). Studies have also shown that microRNA-141 is upregulated in endometrial and colorectal cancers, and the higher the expression, the worse the prognosis is $(9,10)$. In addition, some studies have suggested that microRNA-141 is highly expressed in NPC, but some other studies have reported that microRNA-141 expression is not observed in NPC and adjacent normal tissues (11). At present, the functional role of microRNA-183 and microRNA-141 in NPC is still controversial. This study explored the influence of microRNA-183 and microRNA-141 on prognosis of patients with NPC with an expectation of providing guidance for the diagnosis, treatment and prognosis of NPC and other tumors.

\section{Materials and methods}

General information. A total of 317 NPC patients admitted to Zhengzhou Central Hospital Affiliated to Zhengzhou University (Zhengzhou, China) between January 2010 and March 2016 were selected for this research. Patients included 238 males and 79 females. All patients underwent routine nasopharynx and neck MRI, chest CT, abdominal CT, and bone scans to determine the recurrence and distant metastases. Inclusion criteria: i) age $\geq 18$ years, $\leq 65$ years; ii) patients who had received no radiotherapy or chemotherapy prior to treatment; iii) there were no other malignant tumors or other diseases severely affecting survival; and iv) there were no immediate relatives among the patients. Precautionary and lactating women were excluded. All patients or their relatives 
signed an informed consent. The study was approved by the Ethics Committee of Zhengzhou Central Hospital Affiliated to Zhengzhou University.

Main reagents and instruments. TRIzol RNA extraction kit and miRNA first-strand cDNA synthesis kit (both from Sangon Biotech Co., Ltd., Shanghai, China); SYBR ${ }^{\circledR}$ PrimeScript $^{\mathrm{TM}}$ miRNA RT-PCR kit (Takara Bio, Inc., Otsu, Japan); NanoDrop 2000 (Thermo Fisher Scientific, Inc., Waltham, MA, USA); CFX96 fluorescence quantitative PCR instrument (Bio-Rad Laboratories, Inc., Hercules, CA, USA).

Specimen collection and RNA extraction. NPC tumor and adjacent healthy tissues were collected from NPC patients and were stored in a refrigerator at $-80^{\circ} \mathrm{C}$. Total RNA was extracted from the tissues by using TRIzol RNA extraction kit. The specific extraction steps were as follows: TRIzol was added to lysate cells, followed by centrifugation at $4{ }^{\circ} \mathrm{C}$ $(12,300 \mathrm{x} \mathrm{g})$ for $10 \mathrm{~min}$; supernatant was transferred to a new RNase-free tube, and equal volume of chloroform was added, followed by centrifugation at $4^{\circ} \mathrm{C}(12,300 \mathrm{x} \mathrm{g})$ for 10 min; supernatant was transferred to a new RNase-free tube, and equal volume of isopropanol was added and kept at room temperature for $1 \mathrm{~h}$, followed by centrifugation at $4^{\circ} \mathrm{C}(12,300 \mathrm{x} \mathrm{g})$ for $10 \mathrm{~min}$; supernatant was discarded, and the pellet was washed twice with $75 \%$ ethanol; after air dry, DEPC water was added. NanoDrop 2000 was used to test RNA quality and concentration. RNA with a A260/280 ratio $>1.8$ was subjected to $1.5 \%$ agarose gel electrophoresis to check RNA integrity.

First-strand cDNA synthesis. First-strand cDNA was synthesized according to the instructions of cDNA first strand synthesis kit. The reaction system consisted of $1 \mu 1$ of $2.5 \mathrm{U} / \mu 1$ poly(A) polymerase, $1 \mu \mathrm{l}$ of RTase Mix, $5 \mu \mathrm{l}$ of $5 \mathrm{X}$ PAP/RT buffer, $2 \mu \mathrm{g}$ of total RNA, and RNase free $\mathrm{dH}_{2} \mathrm{O}$ was added to reach a final volume of $25 \mu \mathrm{l}$. Reaction conditions: $37^{\circ} \mathrm{C}$ for $1 \mathrm{~h}$ and $85^{\circ} \mathrm{C}$ for $5 \mathrm{~min}$.

Detection of microRNA-183 and microRNA-141 expression in lesion and adjacent tissues of patients by reverse transcription-quantitative PCR (RT-qPCR). Synthesized cDNA was used as template and U6 as an endogenous control. MicroRNA-183 and microRNA-141 expression levels were detected by RT-qPCR. Reaction system: $10 \mu \mathrm{l}$ of SYBR-Green Master Mix, $0.5 \mu \mathrm{l}$ of upstream and downstream primers, $1 \mu \mathrm{l}$ of cDNA, and $\mathrm{ddH}_{2} \mathrm{O}$ was added to reach a final volume of $20 \mu \mathrm{l}$. MicroRNA-141-F and microRNA-183-F were used as upstream primers, and Uni-miR qPCR Primer in SYBR ${ }^{\circledR}$ PrimeScript $^{\mathrm{TM}}$ miRNA RT-PCR kit was used as downstream primer (Table I). The RT-qPCR reaction conditions were: $95^{\circ} \mathrm{C}$ for $3 \mathrm{~min}$, followed by 40 cycles of $95^{\circ} \mathrm{C}$ for $30 \mathrm{sec}$ and $58^{\circ} \mathrm{C}$ for $1 \mathrm{~min}$. Data were processed using $2^{-\Delta \Delta \mathrm{Cq}}$ method (12).

Statistical analysis. SPSS 17.0 (Beijing Xinmei Jiahong Technology Co., Ltd., Beijing, China) was used for statistical analysis. Measurement data were expressed as mean $\pm \mathrm{SD}$, and t-test was used for the comparison between two groups. Chi-square test was used for comparison of enumeration data. Kaplan-Meier test was used for the survival analysis followed
Table I. Primer sequences.

\begin{tabular}{ll}
\hline Primers (5'-3') & \multicolumn{1}{c}{ Sequences } \\
\hline $\begin{array}{l}\text { Uni-miR qPCR } \\
\text { primer }\end{array}$ & Takara kit \\
MicroRNA-141-F & CGTAACACTGTCTGGTAAAGATGGA \\
MicroRNA-183-F & ACACTCCAGCTGGGTATGGCACTGGTAGAATT \\
U6-F & CTCGCTTCGGCAGCACA \\
U6-R & AACGCTTCACGAATTTGCGT \\
\hline
\end{tabular}

Table II. General clinical data of 317 NPC patients.

\begin{tabular}{lc}
\hline Variable & $\mathrm{n}(\%)$ \\
\hline Age (years) & \\
$\geq 45$ & $156(49.2)$ \\
$<45$ & $161(50.8)$ \\
Sex & \\
Male & $238(75.1)$ \\
Female & $79(24.9)$ \\
Distant metastasis & \\
Unclear & $24(7.6)$ \\
Non-distant metastasis & $136(42.9)$ \\
Distant metastasis & $157(49.5)$ \\
DFS (years) & \\
$\geq 3$ & $172(54.3)$ \\
$<3$ & $145(45.7)$ \\
T period & \\
T1 & \\
T2 & $13(4.1)$ \\
T3 & $43(13.6)$ \\
T4 & $166(52.4)$ \\
N stages & $95(30.0)$ \\
N0 & \\
N1 & \\
N2 & \\
N3 & $91(28.8)$ \\
\hline
\end{tabular}

NPC, nasopharyngeal carcinoma; DFS, disease-free survival.

by a long-rank test. $\mathrm{P}<0.05$ was considered to indicate a statistically significant difference.

\section{Results}

General clinical data. A total of 317 NPC patients admitted to Zhengzhou Central Hospital Affiliated to Zhengzhou University from January 2010 to March 2015 were included. The patients were 238 males and 79 females, aging from 18 to 65 years, with a median age of 45 years. A total of 157 cases presented distant metastasis, 136 cases had no distant metastasis, and distant metastasis was unclear in 24 cases. 
Table III. Expression of microRNA-183 and microRNA-141 in lesions and adjacent tissues (mean $\pm \mathrm{SD}$ ).

\begin{tabular}{lcccc}
\hline Groups & Lesions & $\begin{array}{c}\text { Adjacent } \\
\text { tissues }\end{array}$ & $\mathrm{t}$ & P-value \\
\hline microRNA-183 & $3.11 \pm 0.09$ & $1.21 \pm 0.10$ & 4.771 & 0.041 \\
microRNA-141 & $2.98 \pm 0.12$ & $1.13 \pm 0.08$ & 8.215 & 0.014 \\
\hline
\end{tabular}

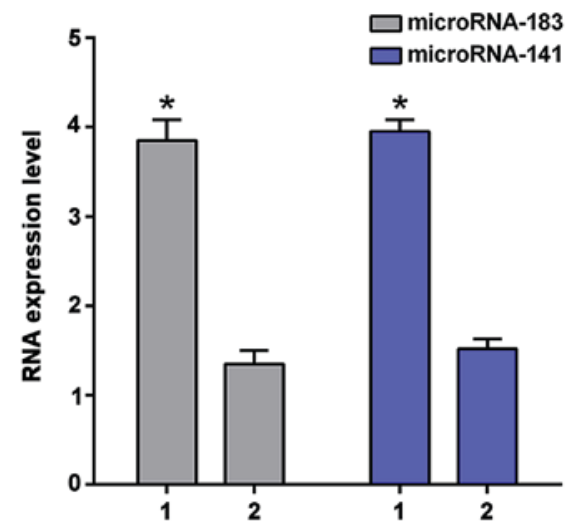

Figure 1. Expression of microRNA-183 and microRNA-141 in patients with and without distant metastasis. The expression of microRNA-183 and microRNA-141 was detected by RT-qPCR. The results showed that the expression levels of microRNA-183 and microRNA-141 were significantly higher in patients with distant metastasis (group 1) than in patients without distant metastasis (group 2). ${ }^{*} \mathrm{P}<0.01$. RT-qPCR, reverse transcription-quantitative PCR

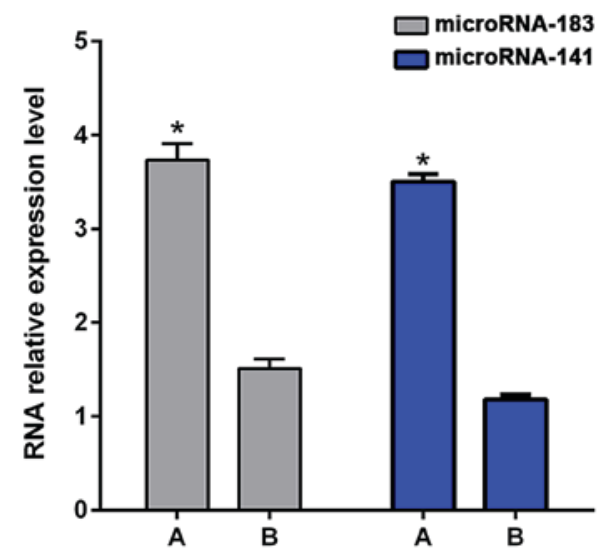

Figure 2. Expression of microRNA-183 and microRNA-141 in patients with different DFSs. The expression of microRNA-183 and microRNA-141 was detected by RT-qPCR. The results showed that the expression levels of microRNA-183 and microRNA-141 in patients with DFS $<3$ years (group A) were significantly higher than those in patients with DFS $\geq 3$ years (group B). " $\mathrm{P}<0.01$. DFS, disease-free survival; RT-qPCR, reverse transcription-quantitative PCR.

In addition, 172 patients had a disease-free survival (DFS) $\geq 3$ years, and 145 patients had DFS $<3$ years. Tumors were confined to the nasopharyngeal area or had infiltrated the pharyngeal soft tissue in 56 cases. Lymph node metastasis occurred in 308 patients (Table II). The 1-, 2-, and 3-year survival rates of the 317 patients were $82.6 \%$ (262), 64.4\% (204), and 54.3\% (172), respectively.

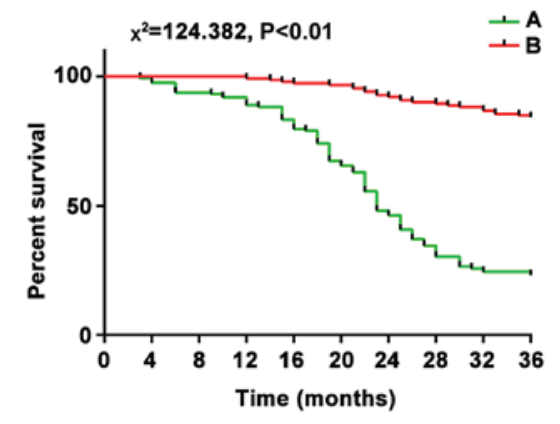

Figure 3. Survival curves of patients with high and low microRNA-183 expression. Group A is the microRNA-183 high expression group (163 cases), and group B is the microRNA-183 low expression group (154 cases). The survival rate of group $\mathrm{B}$ was significantly higher than that of group $\mathrm{A}(\mathrm{P}<0.01)$.

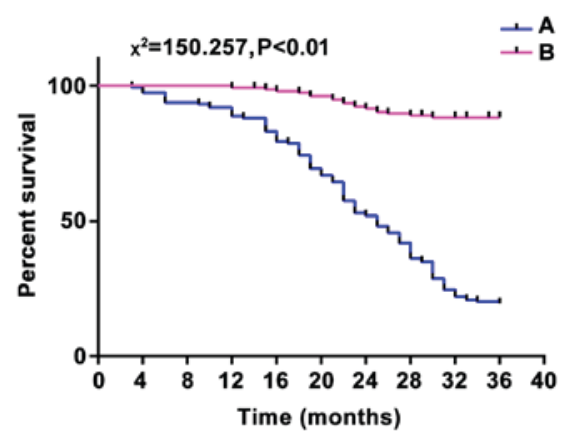

Figure 4. Survival curves of patients with high and low microRNA-141 expression. Group A is the high microRNA-141 expression group (161 cases) and group B is the microRNA-141 low expression group (156 cases). The survival rate of group $\mathrm{B}$ was significantly higher than that of group $\mathrm{A}(\mathrm{P}<0.01)$.

Analysis of the expression levels of microRNA-183 and microRNA-141. The expression of microRNA-183 and microRNA-141 was detected by RT-qPCR. The results showed that the expression levels of microRNA-183 and microRNA-141 in lesion tissues were significantly higher than those in adjacent tissues $(\mathrm{p}<0.05$, Table III). Patients with distant metastases had significantly higher expression levels of microRNA-183 and microRNA-141 (3.85 \pm 0.23 and 3.95 \pm 0.13$)$ than patients without distant metastasis $(1.35 \pm 0.15$ and $1.52 \pm 0.11 ; \mathrm{p}<0.01$, Fig. 1). Patients with DFS $<3$ years showed significantly higher levels of microRNA-183 and microRNA-141 $(3.73 \pm 0.18$ and $3.50 \pm 0.08)$ than patients with DFS $\geq 3$ years $(1.51 \pm 0.10$ and $1.18 \pm 0.05 ;$ p $<0.01$, Fig. 2).

Relationship between microRNA-183 and microRNA-141 and prognosis. The relative expression levels of microRNA-183 and microRNA-141 in the lesion tissue of NPC patients were $2.78 \pm 0.35$ and $2.52 \pm 0.43$, respectively. With the average value as threshold, patients were divided into high and low expression groups. There were 163 cases with high expression of microRNA-183, 154 cases with low expression of microRNA-183, 161 cases with high expression of microRNA-141, and 156 cases with low expression of microRNA-141. After 3 years of follow-up for these patients, 163 patients with high microRNA-183 expression had recurrence and the total number of deaths was 124 (76.1\%), and 154 patients with low microRNA-183 expression had recurrence and the total number of deaths was 21 (13.6\%). A total 
of 161 patients with high expression of microRNA-141 had recurrence and the total number of deaths was 128 (79.5\%), and 156 patients with low expression of microRNA-141 had recurrence and the total number of deaths was 17 (10.9\%). The recurrence and mortality rates of high and low expression groups of microRNA-183 and microRNA-141 were significantly different from each other ( $\chi^{2}$ was 124.382 and 150.257 , respectively; $\mathrm{p}<0.01$ ), suggesting that the high expression of microRNA-183 and microRNA-141 was associated with poor prognosis (Figs. 3 and 4).

\section{Discussion}

The occurrence and development process of NPC is complex, and distant metastasis is an important cause of death in NPC patients (13). Therefore, it is particularly important to explore the relevant molecular mechanisms of NPC distant metastasis.

MicroRNA plays an important role in the invasion of tumor cells. Recent studies have found that microRNA exerts the dual role of oncogenes and tumor suppressor gene in the development of tumors (14).

MicroRNA-183 can inhibit metastasis of cancer cells by inhibiting ezrin protein in lung (15) and breast cancer (16). In addition, it can also inhibit migration of lung cancer cells by downregulating WISP2 protein or upregulating the expression of S100P protein (17). MicroRNA-183 inhibits the expression of cell death factor 4 (PDCD4) in liver cancer and inhibits cell apoptosis (18). MicroRNA-183 inhibits the metastasis of colon cancer cells by inhibiting the expression of EGR1 and PTEN (19). In addition, the role of microRNA-183 in tumors is tissue-specific. MicroRNA-183 can play a tumor suppressive role and can also promote tumor invasion and migration in different cancer cells (20). In this study it was found that the expression level of microRNA-183 in patients with distant metastasis is significantly higher than that in patients without distant metastasis $(\mathrm{p}<0.01)$, suggesting that the expression level of microRNA-183 can be used to predict distant metastasis in NPC patients. When distant metastasis occurs, the expression of microRNA-183 increases, and microRNA-183 plays an important role in promoting the metastasis of tumor cells in NPC. Sarver et al (21) have found that the upregulation of microRNA-183 in colon cancer plays an important role in promoting the development of cancer. In the present study, it was found that the expression level of microRNA-183 in patients with DFS $<3$ years is significantly higher than that in patients with DFS $\geq 3$ years $(p<0.01)$, suggesting that microRNA-183 expression level is related to postoperative survival. At the end of the follow-up, recurrence and mortality were significantly higher in the microRNA-183 high expression group than in the low expression group, suggesting that high microRNA-183 expression is closely related to poor prognosis.

MicroRNA-141 is a member of microRNA-200 family. Xia et al (22) have found that the expression level of microRNA-141 in NPC cell lines with low differentiation is higher than that in highly differentiated NPC cell lines. It was considered that the increase of microRNA-141 expression attributes to NPC occurrence at early stage. In addition, microRNA-141 expression pattern is extremely different in different tumor cells, such as high expression in ovarian cancer (23), and low expression in hepatoma cells (24). In this study, the expression level of microRNA-141 was significantly higher in patients with distant metastasis than in patients without distant metastasis $(\mathrm{p}<0.01)$. Ahmed et al (25) have found that the appearance of lymph node and distant metastasis is accompanied by the increased expression level of microRNA-141, which is consistent with the findings in this study. The expression level of microRNA-141 in patients with DFS $<3$ years was significantly higher than that in patients with DFS $\geq 3$ years $(p<0.01)$. Furthermore, recurrence and mortality of patients with high expression of microR NA-141 were also significantly higher than those of patients with low expression, suggesting that increased expression of microRNA-141 predicts distant metastasis and shortened DFS, and leads to poor prognosis.

In conclusion, microRNA-183 and microRNA-141 can be used as markers for the prediction of distant metastasis of NPC, and have a reference value for the prognosis of NPC. The specific molecular mechanism of microRNA-183 and microRNA-141 in the occurrence and development of NPC remains to be further studied.

\section{Acknowledgements}

Not applicable.

\section{Funding}

No funding was received.

\section{Availability of data and materials}

The datasets used and/or analyzed during the present study are available from the corresponding author on reasonable request.

\section{Authors' contributions}

JL wrote the manuscript. JL and MY were responsible for cDNA synthesis. JL and YL performed PCR. All authors read and approved the final manuscript.

\section{Ethics approval and consent to participate}

The study was approved by the Ethics Committee of Zhengzhou Central Hospital Affiliated to Zhengzhou University (Zhengzhou, China). Signed informed consents were obtained from the patients or the guardians.

\section{Patient consent for publication}

Not applicable.

\section{Competing interests}

The authors declare that they have no competing interests.

\section{References}

1. Chan KC, Hung EC, Woo JK, Chan PK, Leung SF, Lai FP, Cheng AS, Yeung SW, Chan YW, Tsui TK, et al: Early detection of nasopharyngeal carcinoma by plasma Epstein-Barr virus DNA analysis in a surveillance program. Cancer 119: 1838-1844, 2013. 
2. Marsh GM, Youk AO and Morfeld P: Mis-specified and non-robust mortality risk models for nasopharyngeal cancer in the National Cancer Institute formaldehyde worker cohort study. Regul Toxicol Pharmacol 47: 59-67, 2007.

3. Zhang B and Tang PZ: Introduction to $\mathrm{NCCN}$ clinical practice guidelines in head and neck cancer (2009 Chinese version)'. Zhonghua Er Bi Yan Hou Tou Jing Wai Ke Za Zhi 44: 707-709, 2009 (In Chinese).

4. Lee N, Harris J, Garden AS, Straube W, Glisson B, Xia P, Bosch W, Morrison WH, Quivey J, Thorstad W, et al: Intensity-modulated radiation therapy with or without chemotherapy for nasopharyngeal carcinoma: Radiation therapy oncology group phase II trial 0225. J Clin Oncol 27: 3684-3690, 2009.

5. Chen J, Zong J, Wu J and Pan J: Prognostic analysis of nasopharyngeal carcinoma patients with distant metastasis after curative radiotherapy. Zhonghua Zhong Liu Za Zhi 37: 216-221, 2015 (In Chinese)

6. Lin Y, Ukaji T, Koide $\mathrm{N}$ and Umezawa $\mathrm{K}$ : Inhibition of late and early phases of cancer metastasis by the NF- $\mathrm{BB}$ inhibitor DHMEQ derived from microbial bioactive metabolite epoxyquinomicin: A review. Int J Mol Sci 19: 19, 2018.

7. Engels BM and Hutvagner G: Principles and effects of microRNA-mediated post-transcriptional gene regulation. Oncogene 25: 6163-6169, 2006.

8. Ma L, Teruya-Feldstein J and Weinberg RA: Tumour invasion and metastasis initiated by microRNA-10b in breast cancer. Nature 449: 682-688, 2007.

9. Snowdon J, Zhang X, Childs T, Tron VA and Feilotter H: The microRNA-200 family is upregulated in endometrial carcinoma. PLoS One 6: e22828, 2011

10. Cheng H, Zhang L, Cogdell DE, Zheng H, Schetter AJ, Nykter M, Harris CC, Chen K, Hamilton SR and Zhang W: Circulating plasma MiR-141 is a novel biomarker for metastatic colon cancer and predicts poor prognosis. PLoS One 6: e17745, 2011.

11. Xie YJ, Long ZF and He XS: Involvement of EBV-encoded BART-miRNAs and dysregulated cellular miRNAs in nasopharyngeal carcinoma genesis. Asian Pac J Cancer Prev 14 5637-5644, 2013

12. Livak KJ and Schmittgen TD: Analysis of relative gene expression data using realtime quantitative PCR and the 2(-Delta Delta C(T)) method. Methods 25: 402-408, 2001.

13. Ouyang L, Shi Z, Zhao S, Wang FT, Zhou TT, Liu B and Bao JK: Programmed cell death pathways in cancer: A review of apoptosis, autophagy and programmed necrosis. Cell Prolif 45: 487-498, 2012

14. Xiao Z, Ching Chow S, Han Li C, Chun Tang S, Tsui SK, Lin Z and Chen Y: Role of microRNA-95 in the anticancer activity of Brucein D in hepatocellular carcinoma. Eur J Pharmacol 728 : 141-150, 2014.
15. Wang G, Mao W and Zheng S: MicroRNA-183 regulates Ezrin expression in lung cancer cells. FEBS Lett 582: 3663-3668, 2008.

16. Tang R, Li FX, Shao WF, Wen QS, Yu XR and Xiong JB: Protein-protein interaction between ezrin and p65 in human breast cancer cells. Genet Mol Res 15: 15, 2016.

17. Li G, Luna C, Qiu J, Epstein DL and Gonzalez P: Targeting of integrin betal and kinesin 2alpha by microRNA 183. J Biol Chem 285: 5461-5471, 2010.

18. Li J, Fu H, Xu C, Tie Y, Xing R, Zhu J, Qin Y, Sun Z and Zheng X: miR-183 inhibits TGF-betal-induced apoptosis by downregulation of PDCD4 expression in human hepatocellular carcinoma cells. BMC Cancer 10: 354, 2010.

19. Kim J, Kang HS, Lee YJ, Lee HJ, Yun J, Shin JH, Lee CW, Kwon BM and Hong SH: EGR1-dependent PTEN upregulation by 2-benzoyloxycinnamaldehyde attenuates cell invasion and EMT in colon cancer. Cancer Lett 349: 35-44, 2014.

20. Meng F, Li Z, Yan J, Manjanatha M, Shelton S, Yarborough S and Chen T: Tissue-specific microRNA responses in rats treated with mutagenic and carcinogenic doses of aristolochic acid. Mutagenesis 29: 357-365, 2014.

21. Sarver AL, Li L and Subramanian S: MicroRNA miR-183 functions as an oncogene by targeting the transcription factor EGR1 and promoting tumor cell migration. Cancer Res 70: 9570-9580, 2010.

22. Xia H, Ng SS, Jiang S, Cheung WK, Sze J, Bian XW, Kung HF and Lin MC: miR-200a-mediated downregulation of ZEB2 and CTNNB1 differentially inhibits nasopharyngeal carcinoma cell growth, migration and invasion. Biochem Biophys Res Commun 391: 535-541, 2010.

23. van Jaarsveld MT, Helleman J, Boersma AW, van Kuijk PF, van Ijcken WF, Despierre E, Vergote I, Mathijssen RH, Berns EM, Verweij J, et al: miR-141 regulates KEAP1 and modulates cisplatin sensitivity in ovarian cancer cells. Oncogene 32: 4284-4293, 2013.

24. Xue J, Niu YF, Huang J, Peng G, Wang LX, Yang YH and Li YQ: miR-141 suppresses the growth and metastasis of HCC cells by targeting E2F3. Tumour Biol 35: 12103-12107, 2014.

25. Ahmed FE, Amed NC, Vos PW, Bonnerup C, Atkins JN, Casey M, Nuovo GJ, Naziri W, Wiley JE and Allison RR: Diagnostic microRNA markers to screen for sporadic human colon cancer in blood. Cancer Genomics Proteomics 9: 179-192, 2012.

This work is licensed under a Creative Commons Attribution-NonCommercial-NoDerivatives 4.0 International (CC BY-NC-ND 4.0) License. 